\title{
Mexico: the Inaugural International Chapter of the Society for Surgery of the Alimentary Tract
}

\author{
Eduardo E. Montalvo-Jave ${ }^{1,2} \cdot$ Edwin A. Ayala-Moreno ${ }^{2} \cdot$ Nathaniel J. Soper $^{3} \cdot$ Stanley W. Ashley ${ }^{4} \cdot$ Steven Stain $^{5}$. \\ Timothy M. Pawlik ${ }^{6}$. Carlos Pellegrini ${ }^{7}$. John L. Cameron ${ }^{8}$. Jean N. Vauthey ${ }^{9} \cdot$ Daniel Jones $^{10} \cdot$ Michael G. Sarr $^{11}$. \\ Mark P. Callery ${ }^{10}$. Samuel Shuchleib Chaba ${ }^{12}$
}

Received: 20 December 2021 / Accepted: 29 December 2021 / Published online: 12 January 2022

(c) The Society for Surgery of the Alimentary Tract 2022

Keywords Surgery $\cdot$ Alimentary tract $\cdot$ Society surgery $\cdot$ Research

The Society of Surgery of the Alimentary Tract (the SSAT) had its origin in the late 1950 s, created by a group of academic surgeons from well-known surgical centers in the USA. The objective then was to establish a surgical organization dedicated to the scientific study of the alimentary tract with a strong focus on research and education. From its inception, the SSAT has shown its interest in collaborating with other associations both within and outside the USA to pursue this same founding mission. ${ }^{1-3}$

We greatly appreciate the opportunity to present this announcement and the ability for Mexican GI Surgeons to participate actively going forward with the SSAT. Mexico will become the first international chapter of the SSAT. By now, even with the COVID-19 pandemic, this has occurred within the framework of the 2021 SSAT virtual congress with Digestive Disease Week, and the annual International Congress of the Mexican Association for Digestive Surgery (Asociación Mexicana de Cirugía del Aparato Digestivo

Eduardo E. Montalvo-Jave

montalvoeduardo@hotmail.com

1 HPB Clinic, Department of General Surgery, Hospital General de Mexico "Dr. Eduardo Liceaga", Dr. Balmis 148, Colonia Doctores, Alcaldia Cuahtemoc, Mexico City, Mexico

2 Department of Surgery, Faculty of Medicine, UNAM, Mexico City, Mexico

3 Department of Surgery, Department of Surgery, University Medical Center Phoenix, Phoenix, AZ, USA

4 Department of Surgery, Brigham \& Women's Hospital, Boston, MA, USA

5 Department of Surgery, Lahey Hospital and Medical Center, Burlington, MA, USA
- AMCAD) that was to be held in August, in Acapulco, Mexico. $^{4}$

The pathway to the establishment of this Mexican SSAT Chapter began 2 years ago with encouragement and thanks to Drs. Nathaniel Soper, Stanley Ashley, Carlos Pellegrini, and Mark Callery and many other leaders who supported us in this multinational academic collaboration built around excellence. ${ }^{5-7}$ After multiple promotional activities within Mexico and the strong support of AMCAD, the IX congress of AMCAD was held in Mexico City from July 31 to August 3, 2019, in the main auditorium of Hospital Médica Sur; this meeting marked the formal start of this successful academic collaboration (Image 1).

At this inaugural event, an extraordinary group of foreign and Mexican GI surgeons attended and participated. Twenty-two International Faculty including professors and representatives from Europe, Latin America, USA, and more than 50 Mexican professors shared their knowledge. This

6 Department of Surgery, Ohio State University, Columbus, OH, USA

7 Department of Surgery, University of Washington, Seattle, WA, USA

8 Department of Surgery, Johns Hopkins School of Medicine, Baltimore, USA

9 Department of Surgical Oncology, MD Anderson Cancer Center, Houston, TX, USA

10 Department of Surgery, Beth Israel Deaconess Medical Center, Boston, MA, USA

11 Department of Surgery, Mayo Clinic, Rochester, MN, USA

12 Department of Surgery, Medical Center ABC, Mexico City, Mexico 


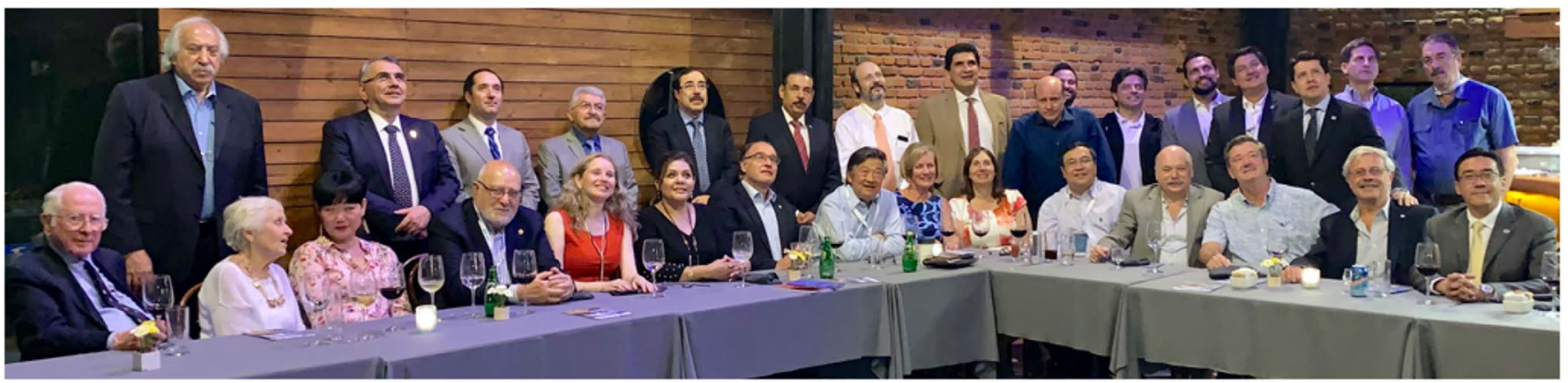

Image 1 The Mexican Chapter of the SSAT was launched in August 2019 during the 9th Congress of the Asociación Mexicana de Cirugía del Aparato Digestivo (AMCAD) in Mexico City

venue (and hopefully more to come in the future) provided nearly 800 attendees and participants with a unique opportunity to interact both scientifically and socially, to learn, and to disseminate cutting-edge surgical knowledge between the various scientific groups.

A highly interactive program enabled Mexican surgeons and residents with oral presentations and posters to present outstanding clinical and scientific content.as well as the presentation of posters. Keynote lectures by experts around the world coordinated by leading professors and surgeons of various specialties in the field of digestive tract surgery were all fully attended over 3 days. The keynote lectures focused on specific issues of abdominal pathology, with professors from the USA, Mexico, Argentina, Colombia, Peru, and Switzerland addressing several points of view and advances, such as transplantation, pancreatic and liver surgery, robotic surgery, gallbladder and bile duct surgery, gastroesophageal surgery, colorectal surgery, robotic surgery, and technological advances, as well as recent new knowledge in medical and biomedical sciences.

All sessions of this program were integrated with the various Mexican associations and colleges, such as the Mexican College of Obesity Surgery (CMCOEM), Mexican Association of Endoscopic Surgery (AMCE), Mexican Hepato-Pancreato-Biliary Association (AMHPB), Mexican Association of Gastroenterology (AMG), Mexican Association of General Surgery (AMCG), Mexican Association of Endoscopic Surgery (AMCE), College of Specialists in General Surgery of Mexico City (CECGCDMX), and the Mexican Academy of Surgery (AMC). It was undoubtedly a great academic event, which we plan to continue to promote in our scientific community. The successful academic collaboration of the SSAT across Mexican GI Surgery will foster the dissemination of medical-surgical knowledge. We expect also that this chapter will grow and continue to include various national societies and associations within Mexico. Importantly, this international congress had the endorsement of the School of Medicine of the National Autonomous University of Mexico (UNAM), the Mexican Academy of Surgery (Academia Mexicana de Cirugía), and SSAT.
The Mexican Chapter of the SSAT is its first such academic chapter outside the North America and hopefully will ignite the launch of other international collaborating chapters. Our new Mexican chapter of the SSAT currently has 220 active members, consisting primarily of Mexican surgeons interested in digestive surgery, who have the privilege of belonging to such an important international surgical association.

For those in Mexico still excited to learn more: The SSAT conducts its courses and congress annually together with the American Gastroenterology Association (AGA), the American Society for Gastrointestinal Endoscopy (ASGE), and the American Association for the Study of Liver Diseases (AASLD), usually in May. These 4 societies work together to maximize interaction via combined programs and courses, free paper sessions, posters sessions, individual plenary sessions, and joint symposia covering medical-surgical issues of digestive diseases. The congress is heralded worldwide as Digestive Disease Week (DDW).

Today, the Mexican chapter of the SSAT has become a reality and has been registered as a legal entity in Mexico (Image 2). This formal association will undoubtedly stimulate more Mexican surgeons to join the Mexican Chapter of the SSAT and should serve as an example for the establishment of SSAT chapters in other Latin American countries. New Mexican members of the SSAT (and thus of the Mexican Chapter of the SSAT) have now become possible, because as all its members are surgeons affiliated with the Mexican Association of General Surgery (AMCG) and the Latin American Federation of Surgery (FELAC). Therefore, becoming a member of both the Mexican chapter of the SSAT as well as the SSAT with all its member benefits will prove to be simple. We will conduct our chapter in cooperation with the various other Mexican general and abdominal surgery associations to facilitate new members joining the SSAT with minimal hindrances. The current directors of the SSAT have been very supportive of collaborating and participating with us, having authorized us to use the SSAT logo in the scientific program, posters, and academic promotion 


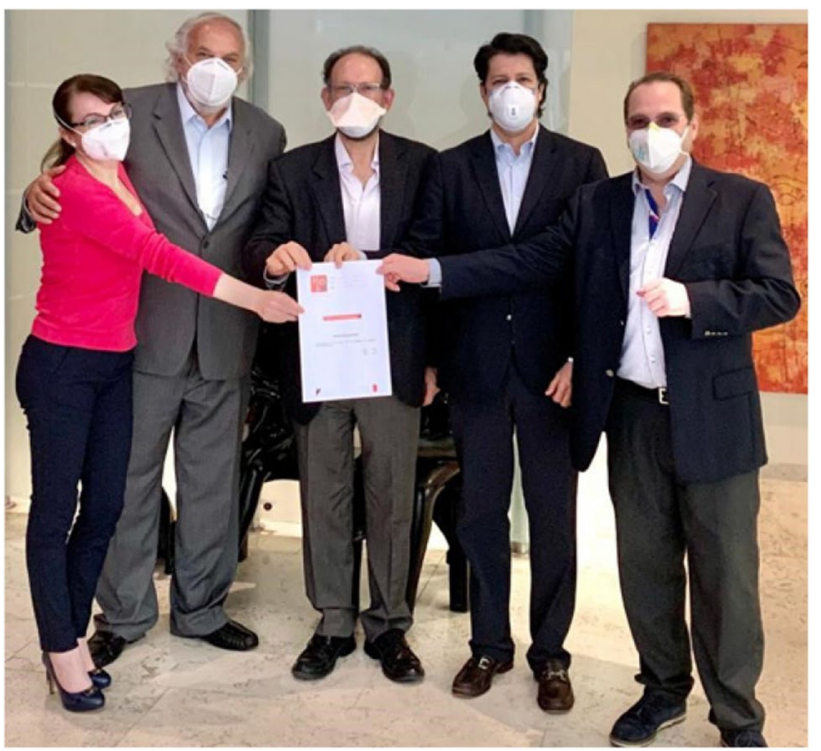

Image 2 SSAT Mexican Chapter Legally registered. From left to right: Gabriela Alarcon MD; Samuel Shuchleib-Chaba MD; Samuel Kleinfinger-Marcuschamer MD; Eduardo Montalvo-Jave MD, PhD; Enrique Stoopen MD

in general as well as our participation in many national Mexican congresses of digestive tract surgery, endoscopic surgery, and general surgery.

Despite the barriers imposed by the SARS CoV-2 pandemic, the Mexican chapter of the SSAT hosted the "SSAT Clinical Case Management International Webinar" carried out on September 10th, 2020. A total of 508 attendees registered for this event, in which three clinical cases were presented by recognized surgeons: (1) Pancreatic cancer by Dr. Carlos Chan Nuñez; (2) Multifocal Liver Metastasis for Colon Cancer by Dr. Jean Nicolas Vauthey; and (3) Giant Paraesophageal Hernia by Dr. Gaby Adriana Alarcon-Jersun. Likewise, a list of approximately 15 American and 10 Mexican surgeons participated as panelists discussing these cases which proved to be an outstanding academic exercise for the attendees.

Continuing with the academic efforts throughout the global pandemic, the Mexican Chapter of the SSAT hosted the "SSAT International Webinar 2021" (Image 3) on April 15 th with the special participation of Dr. Go Wakabayashi and his Keynote Lecture "Importance of the Tokyo Guidelines in Acute Cholecystitis and Cholelithiasis." This international meeting registered an extraordinary 3006 attendees. Within the panel of surgeons who were part of this International Webinar, 10 Mexican and 5 American surgeons contributed their valuable comments to the excellent lecture of Dr. Wakabayashi.

In addition, our Mexican chapter of the SSAT has participated in several National Congresses, specifically in the National Congress of the Mexican Association of General

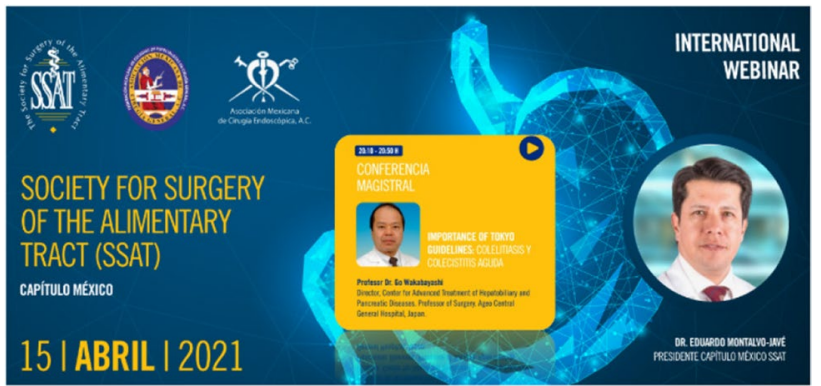

Image 3 SSAT International Webinar 2021

Surgery (AMCG), Mexican Association of Endoscopic Surgery (AMCE), Mexican Association of Digestive Tract Surgery (AMCAD), and the Mexican Academy of Surgery (AMC) in 019 and 2020 as well as the Congresses hosted by the AMCE and AMCAD in 2021. Our participation involved a symposium with national professors who are members of the Mexican Chapter and foreign guest speakers who are members of the SSAT.

We view this collaboration between the SSAT and our Mexican chapter of the SSAT as being of great relevance to the education of Mexican surgeons as well as their participation in the yearly SSAT meeting in the USA. This cooperation will yield benefits for the new members who will gain access to the online Journal of Gastrointestinal Surgery (JGOS), as well as important preferential rates for attending the courses and annual congress of the Digestive Disease Week. The Strategic Plan of the SSAT for the next decade consists of an ambitious project with a clear objective of improving in the short-, medium-, and long-term mission of this organization in collaboration with our chapter and additional new international chapters like ours.

Despite all the challenges and far-reaching adverse events we are currently living with because of the SARS CoV-2 pandemic, this academic collaboration has produced great results, especially for our young trainees who have worked since youth to begin their careers in GI Surgery. Now we can and do provide global interactive webinars with thought leaders and academic exchange with professors, scholarships, clinical rotations, and current and future clinical research projects. These are just part of the SSAT set of values we are proud to embrace in Mexico.

\section{References}

1. Stain S. 2019 SSAT Presidential Address: the Path Forward. Journal of Gastrointestinal Surgery. 2019;24(1):209-211.

2. Kennedy G, Lidor A, Jeyarajah D, Walsh M, Hassan I, Soper $\mathrm{N}$ et al. Looking Ahead: the SSAT Strategic Plan Version 2.0 
for the Next Decade. Journal of Gastrointestinal Surgery. 2019;24(11):2441-2446.

3. Rattner D, Mahvi D, Hunter J. Looking Ahead: The SSAT Strategic Plan for the Next Decade. Journal of Gastrointestinal Surgery. 2011;15(7):1077-1085.

4. Montalvo-Javé. Creating new strategies and academic alliance with the SSAT. Mexican Journal of the Alimentary Tract. 2018; 7(4): 109-110

5. DeMeester T. Change, relationships, and accountability: marks of a vibrant society. Journal of Gastrointestinal Surgery. 1998;2(1):2-10.
6. Soper N. SSAT Presidential Address 2017 "Passion and the GI Surgeon". Journal of Gastrointestinal Surgery. 2017;22(1):1-7.

7. Ashley S. SSAT Presidential Address: Whereof What's Past Is Prologue. Journal of Gastrointestinal Surgery. 2018;23(1):1-10.

Publisher's Note Springer Nature remains neutral with regard to jurisdictional claims in published maps and institutional affiliations. 